\title{
Household Energy Utilization Trends in Kenya: Effects of Peri Urbanization
}

\author{
Stephen K. Kimutai and Stephen M. Talai
}

\section{ABSTRACT}

\begin{abstract}
Household energy utilization trends have been argued to be affected by the rate of urbanization. Therefore, due to lack of information there is need to understand the effects of peri urbanization. The main objective of this research was to investigate household energy utilization trends and the effects of peri urbanization on household energy utilization and changing behaviour. The research was carried out in the counties of Bungoma and Uasin-Gishu of Kenya. Random sampling technique was used to select 560 households from a target household of 663,739 and data was collected using a structured questionnaire. The results showed that firewood is still the most common energy resource used for cooking in both rural and peri urban areas as evidenced by responses of $87.5 \%$ and $72.4 \%$, respectively. The use of LPG (26 to $42 \%)$, charcoal $(39.4 \%$ to $53.8 \%)$ and kerosene $(14.3 \%$ to $17.3 \%)$ for cooking were found to increase as one move from rural to peri-urban and vice versa for agricultural residues $(12.3 \%$ to $5.3 \%)$. Biogas uptake still represents a small fraction (11.4 to $14.6 \%$ ) of the energy mix at local level. The use of solar for lighting showed reduction as one move from rural to peri urban $(44.8 \%$ to $39.6 \%)$ and vice versa for kerosene $(68.4 \%$ to $72 \%)$ and electricity $(55.5 \%$ to $58.2 \%)$. In conclusion, this study showed that household energy utilization and changing behaviour in Kenya are affected by peri urbanization among others. This study offers understandings in enhancing household energy policy making in Kenya.
\end{abstract}

Keywords: Household, fuel, peri-urbanization, rural, cooking and lighting.
Published Online: June 21, 2021

ISSN: 2736-5506

DOI : 10.24018/ejenergy.2021.1.2.9

Stephen K. Kimutai*

Department of Mechanical, Production \& Energy Engineering, School of Engineering, Moi University, Kenya. (e-mail: mantuikong@gmail.com) Stephen M. Talai Department of Mechanical, Production \& Energy Engineering, School of Engineering, Moi University, Kenya. (e-mail: stevetalai@gmail.com)

*Corresponding Author

\section{INTRODUCTION}

A growing portion of Africa's population is expected to live in cities and towns by 2030 . Whereas urban areas comprise 472 million people at present, it is expected that this number will double over the next 25 years as more people will be pushed out of rural areas [1]. Interestingly, the rate of urbanization is projected to increase from $41 \%$ in 2016 to $51 \%$ in 2040 [1], [2]. It is likely to be accompanied by a rise in appliance and vehicle use and increased demand for modern household energy use, including energy-intensive products such as Liquified Petroleum Gas (LPG) and electricity [3]-[5]. However, lack of access to electricity may form a major barrier to urban development and Africa's economic development in general.

Electricity access is the lowest in Sub-Saharan Africa, both in urban and rural areas, with rates at $58 \%$ and $12 \%$ respectively [5]-[8]. Households in cities and surrounding rural areas differ in energy use and supply needs.

Whereas urban dwellers use relatively less firewood compared to their rural neighbors, they typically employ more charcoal which is usually cheap and readily available. Various energy studies on Sub-Saharan Africa confirm an increase in charcoal consumption with rising urbanization levels [9]-[12].

Literature on the effect of peri urbanization on household energy utilization and changing behaviour is still scarce. Many scholars have paid special attentions to the relationship between socio economic factors such as income and energy consumption, hence there is need to understand the role and effects of peri urbanization on household energy utilization and changing behaviour. A better understanding of the different factors that affect the household energy utilization will help to design interventions by both Governmental and Non-Governmental organizations working on energy and energy related issues [13]. This study contributes to the limited but growing empirical evidence of household energy factors affecting the utilization of household energy sources.

According to the theoretical explorations, urbanization and industrialization exert impact on energy problems in two main ways: First, the construction and use of abundant infrastructures, buildings, and security during urbanization increase energy consumption and have a negative impact on climate change. Secondly, the economies of scale for energy supply and concentrated use of energy consumption caused by population agglomeration and urbanization, as well as industrial structure optimization, technological innovation, and updating of consumption brought by industrialization, increase energy utilization, thus affecting the energy utilization and changing behaviour [14].

It is believed that housing development in most peri urban is mostly characterized by a high level of informal development, poor quality housing and confronted with a 
multi-dimensional environmental and socio-cultural challenges [15]-[17]. Furthermore, grid electricity is usually available in cities, yet, it is not accessible to all particularly the urban poor (i.e., slums) who mostly live at neglected localities deprived of basic infrastructure [18]. In rural areas, homesteads are often dispersed and consequently, not connected to grid electricity because of high transmission and distribution costs associated with grid extension [19]. The latter is particularly evident in Eastern and Southern Africa where the majority of the rural population resides in dispersed homesteads [20]. As a consequence, rural households resort to conventional energy sources, yet at the same time, rural areas are perceived as the ideal place for deployment of new and innovative electrification technologies such as those based on solar energy [20].

Peri urbanization is an important factor that affects the pattern of energy consumed in developing countries especially Kenya [18], [21]. Kenya's current urbanization rate of $27.8 \%$ [1] and it is estimated that nearly half (44\%) of the entire population of Kenya will be urban by the year 2050 [22]. It is believed that as a given area becomes urbanized or per urbanized, the level of household energy utilization also changes. This research was carried out in the counties of Bungoma and Uasin Gishu, both located in Kenya's semihumid region, with the selection of both counties under the guidance of the A Sustainable Approach Livelihood (ASALI) project and experts at the Kenya Forestry Research Institute (KEFRI) [23]. Therefore, the aim of this paper was to untangle the effect of peri urbanization on household energy utilization and changing behaviour in Kenya.

\section{RESEARCH AREA AND METHODS}

The study was conducted among rural and peri-urban households in two counties with dissimilar levels of peri urbanization and forest coverage, i.e., Bungoma (percent urban population: $22 \%$; forest cover as percent cover of total county area: $21 \%)$ and Uasin Gishu (39\%; 11\%), in Kenya. Selection of both counties as study area was steered by the following: the ASALI project and experts at the Kenya Forestry Research Institute (KEFRI) and researchers who carried out a baseline survey to identify the regions within the country where critical ecosystem services for human well-being are stressed [24], [25]. Moreover, the level of urbanization and availability of forest resources, using forest area as indicator, served as criteria for site selection.

Bungoma County is situated in Western Kenya; its geographical coordinates are $0^{\circ} 34^{\prime} 0^{\prime \prime}$ North, $34^{\circ} 34^{\prime} 0^{\prime \prime}$ East. It covers an area of $3,032.2 \mathrm{~km}^{2}$. According to the 2019 Kenya Population and Housing Census the population is $1,670,570$ and has 358,796 households (KNBS, 2019). On the other, Uasin Gishu County is situated in the former Rift Valley Province. Its geographical coordinates are $0.5528^{\circ} \mathrm{N}$, $35.3027^{\circ} \mathrm{E}$ shares some rather short borders with Bungoma County to the West. It occupies an area of $3,345 \mathrm{Km}^{2}$ with a population of 1,163,186 people and 304,943 households (KNBS, 2019). The County's headquarters is Eldoret town that boasts of population taking just over $32 \%$ of the county's population.
The study targeted a total number of 304,943 and 358,796 households in Uasin Gishu and Bungoma counties respectively (KNBS, 2019). The stratified random sampling technique was used to select a sample of 560 rural and peri-urban households in total. Data on household energy utilization behavior was collected by means of a household survey, using a structured questionnaire. Likewise, focus group discussions with local communities in both counties were conducted to provide additional background information on household fuel utilization.

\section{A. Research Hypothesis}

The research question revolved around the difference in household fuel utilization between rural and Peri urban hypothesis within the context of Kenya.

\section{RESULTS AND DISCUSSION}

\section{A. Trend of Household fuel for Cooking}

Fig. 1 presents the percentage of households that use specific kind of household energy source for cooking between peri urban and rural areas in the study area. The proportion of households that use fire wood declines from $87.5 \%$ to $72.4 \%$ as one moves from rural to peri-urban, while the use of charcoal increases from $39.4 \%$ to $53.8 \%$ in the same case. On the other hand, the use of LPG and kerosene increases from $26 \%$ and $39.4 \%$ to $42 \%$ and $53.8 \%$, respectively.

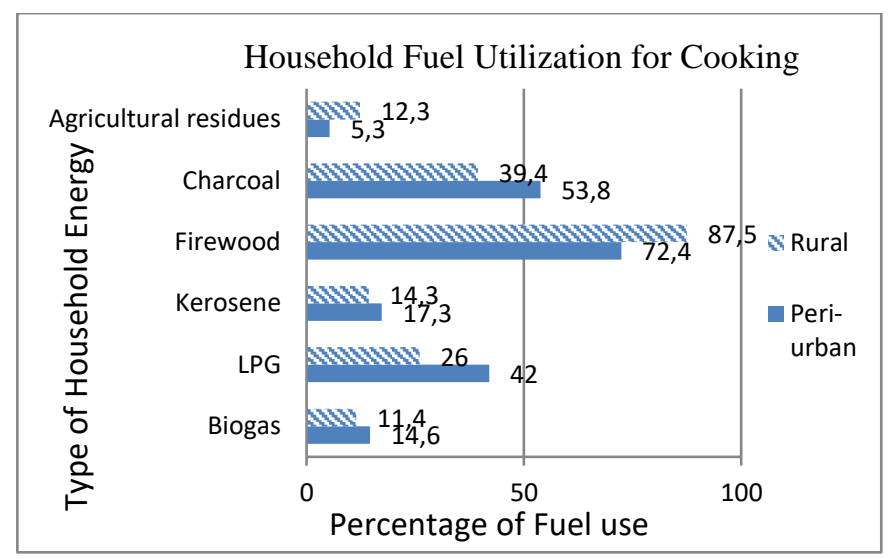

Fig. 1. Household Energy for cooking by households.

The results also show the reduced use of modern fuels such as LPG and charcoal among rural households. This was attributed to the heavy dependence of these households on biomass energy for cooking among rural settlements. The findings are in line with the observation that households in rural areas were observed collecting their firewood rather than purchasing, reflective of the occasional use. In addition, the results showed that although biogas technology uptake is still low as it represents a small fraction of the energy mix at local level. Furthermore, households in peri-urban have significantly higher fuel choices than households in the rural areas with firewood and charcoal are the most common combination of multiple fuel use for both peri urban and rural households. These results are in agreement with the findings of previous studies where firewood was found to be a key source of energy for rural dwellers in developing countries Edwards and Langpap [26], [27]-[31] and Duguma, Atela [32]. 
Among the rural households, firewood remains the main fuel source signifying that majority households still depend on firewood for their cooking needs. Households using liquid fuels (LPG), charcoal, and kerosene are mostly found in periurban areas. Notably, there is a shift towards charcoal, LPG and kerosene as one moves from the rural to peri-urban areas and these findings corroborates the research done by Hanif [11], Wang and Dong [12] and Arnold and Persson [9]. Nonetheless, the experimental evidence in the study is in support of the energy stacking model rather than the energy ladder model - of household fuel utilization which suggests that households do shift to superior fuels but do not abandon the inferior fuels altogether [29], [33]. The results of biogas utilization indicates its low consumption on social-economic and environment development among the local communities which concurs with the research done by Katikiro [34], Ouedraogo [27], Sana, Kafando [35].

Appendix II presents the pairwise correlation coefficients which reveal the relationship between the household energy choices made by the households for cooking. They include; firewood, charcoal, kerosene, LPG, biogas and agricultural residues. For rural, the results revealed a positive and significant association between the use of firewood agricultural residues $(0.103 *)$, LPG - charcoal $(0.361 * * *)$, biogas - LPG $(0.144 * * *)$ and charcoal -biogas $(0.189 * * *)$ while on the other hand negative and significant association between the use of charcoal - firewood (-0.546), LPGfirewood $\left(-0.095^{*}\right)$, firewood - kerosene $\left(-0.335^{* * *}\right)$ and biogas - firewood (- 0.073) among the rural households. The results indicate that the households tend to choose dirty, transitional and modern energy sources in bundles.

On the other hand, the results for peri urban show positive and significant association between the use of firewood agricultural residues $(0.111 * * *), \mathrm{LPG}-\operatorname{charcoal}(0.289 * * *)$, and charcoal - kerosene $(0.230 * * *)$, while a negative and significant association between the use of firewood - charcoal $\left(-0.454^{* * *}\right)$, LPG - firewood $\left(-0.448^{* * *}\right)$, LPG- kerosene ($0.038 * * *)$, firewood - kerosene $(-0.364 * * *)$, LPGagricultural residues $\left(-0.19^{* *}\right)$, kerosene - agricultural residues $\left(-0.208^{* *}\right)$ and biogas -kerosene $\left(-0.207^{* * *}\right)$ is observed. The peri urban result shows a positive correlation among the low-quality energy source, transitional and clean/modern energy sources and also a negative relationship is observed between low quality energy source, transitional and clean/modern. The results further more show a negative and significant pairwise correlation between firewood charcoal and LPG - firewood signifying the general reduction of fire wood with peri urbanization.

Moreover, the results on household energy for cooking by households support the fuel stacking energy utilization model than energy ladder in study households which can be presented as shown in Fig. 2.

\section{B. Trend of Household fuel use for Lighting}

Fig. 2 presents results on the percentage of households that use a specific type of household energy source for lighting. It showed a reduction tendency of solar use as one move towards peri urban (from $44.8 \%$ to $39.6 \%$ ). However, the use of kerosene (68.4\% to $72 \%$ ) and electricity (55.5\% to $58.2 \%)$ also increases as households move from rural to peri urban areas. The pattern of energy use for lighting shows that there is a small difference in the use of kerosene and solar between the rural and peri urban households. The results are in agreement with the findings of Maharaj [36] and [18]. The sampled households with access to the electrical network used a variety of backup lighting sources (such as solar, mobile phone light, candles, and kerosene lamp) to enhance energy security. For instance, in rural areas, it revealed that in addition to solar, kerosene fueled lamps is used for enhancing the energy security. Furthermore, it was found that the solar lantern form of light was common due to the fact that it is faster and easier to turn for sudden need than the more complicated task of lighting a kerosene lamp and it can be used in wind or rain. These results are in agreement with the findings of Munro [37] and [38].

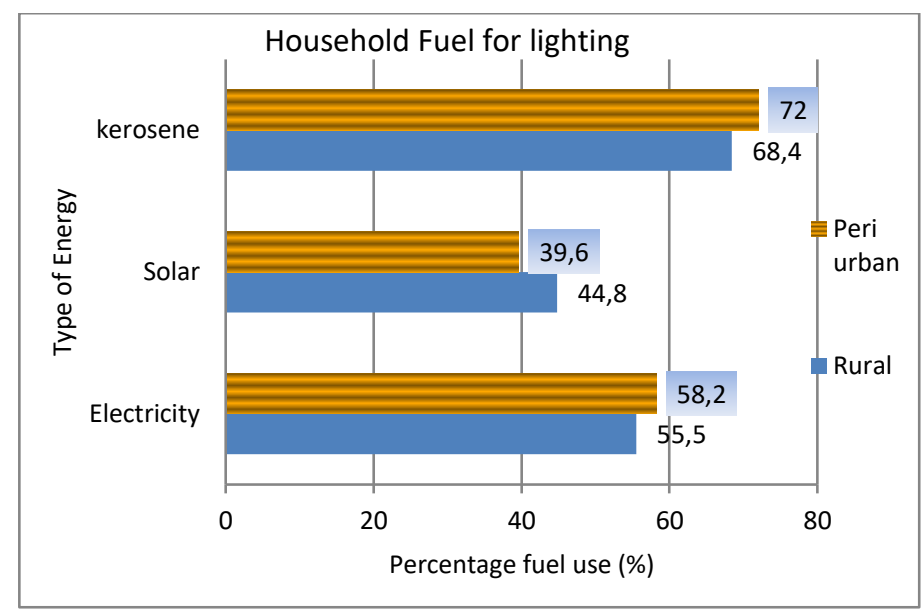

Fig. 2. Sources of household fuel for lighting.

TABLE I: CORRELATION COEFFICIENTS OF THE HOUSEHOLd FuEL SOURCE

\begin{tabular}{ccccc}
\multicolumn{5}{c}{ FOR LIGHTING } \\
\hline Area/ Household energy & Solar & Kerosene & Electricity \\
\hline \multirow{2}{*}{ Rural } & Solar & 1.000 & $0.136^{* *}$ & $-0.244^{* * *}$ \\
& Kerosene & $0.136^{* *}$ & 1.000 & $-0.520^{* * *}$ \\
& Electricity & $-0.244^{* * *}$ & $-0.520^{* * *}$ & 1.000 \\
\multirow{2}{*}{ Peri } & Solar & 1.000 & .095 & $0.408^{* * *}$ \\
urban & Kerosene & 0.095 & 1.000 & $-0.511^{* *}$ \\
& Electricity & $-0.408^{* * *}$ & $-0.511^{* * *}$ & 1.000 \\
\hline \multirow{*}{*}{$* * * * *$} & and $*$ indicate significance at the $1 \%$ and $5 \%$ and $10 \%$ levels,
\end{tabular}
respectively.

The pairwise correlation coefficients of the household energy sources result for lighting are shown in Table 1. For rural, the results showed a positive and significant association between the use of solar - kerosene $\left(0.136^{* *}\right)$ while on the other hand negative and significant association between the use of solar - electricity $\left(-0.244^{* * *}\right)$ and kerosene - electricity $(-0.520 * * *)$ implying that the majority of rural households use solar and kerosene as a source of energy for lighting. For peri urban, it was found that there is negative association between solar - electricity $(-0.408 * * *)$ and kerosene - electricity $(-0.511 * * *)$. The findings indicate that the majority of rural households rely on solar and kerosene while peri urban households majorly depend on electricity and solar as back up. The results are in line with Behera and Ali [39] and [40].

\section{CONCLUSION}

In conclusion, regardless of the efforts to encourage the use of biogas in Kenya, their adoption level and use is still low with firewood and charcoal as the most common combination of multiple fuel use for both peri urban and rural households. 
This research has demonstrated that in addition to income, education and other household characteristics, peri urbanization showed interesting effects on the household energy utilization and changing behaviour. Since the study considered Bungoma and Uasin Gishu counties of Kenya, the data obtained may not be representative of the real situation in other parts of the country. Therefore, a similar study should be carried out in other areas in Kenya to establish if the same results would be obtained. It is thus recommended that since data were collected from different location with different demographic factors (such as education, income, and consumers' awareness) which may vary from peri urban to rural areas. Future research work be conducted separately rural and peri urban areas of the counties with a larger sample size.

\section{APPENDIX}

\author{
Appendix I: Fig. 3
}

Appendix II: Table II



Fig. 3. Household fuel transition model for the study area.

TABLE II: CORRELATION'S COEFFICIENTS OF HOUSEHOLD ENERGY SOURCES FOR COOKING

\begin{tabular}{|c|c|c|c|c|c|c|c|}
\hline & Area/Fuel & LPG & Firewood & Charcoal & Kerosene & Biogas & $\begin{array}{l}\text { Agricultural } \\
\text { Residue }\end{array}$ \\
\hline \multirow{6}{*}{ Rural } & LPG & 1 & $-0.095^{*}$ & $0.361^{* * *}$ & -0.049 & $0.144^{* * *}$ & $-0.195^{* * *}$ \\
\hline & Firewood & -0.095 & 1 & $-0.546^{* * *}$ & $-0.335^{* * *}$ & -0.073 & $0.103 *$ \\
\hline & Charcoal & $0.361^{* * *}$ & $-0.546^{* * *}$ & 1 & $0.240^{* * *}$ & $0.189^{* * *}$ & $-0.300^{* * *}$ \\
\hline & Kerosene & -0.049 & $-0.335^{* * *}$ & $0.240^{* * *}$ & 1 & 0.067 & $-0.198^{* * *}$ \\
\hline & Biogas & $0.144^{* * *}$ & -0.073 & $0.189^{* * *}$ & 0.067 & 1 & $-0.112 * *$ \\
\hline & Agricultural Residue & $-0.195^{* * *}$ & 0.103 & $-0.300^{* * *}$ & $-0.198^{* * *}$ & $-0.112^{* *}$ & 1 \\
\hline \multirow{6}{*}{$\begin{array}{c}\text { Peri } \\
\text { urban }\end{array}$} & LPG & 1 & $-0.448^{* * *}$ & $0.289^{* * *}$ & -0.038 & -0.024 & $-0.190^{* * * *}$ \\
\hline & Firewood & $-0.448^{* * *}$ & 1 & $-0.454^{* * *}$ & $-0.364^{* * *}$ & 0.036 & $0.111^{*}$ \\
\hline & Charcoal & $0.289^{* * *}$ & $-0.454^{* * *}$ & 1 & $0.230^{* * *}$ & 0.106 & $-0.208^{* * * *}$ \\
\hline & Kerosene & -0.038 & $-0.364^{* *}$ & $0.230^{* *}$ & 1 & $-0.207^{* *}$ & -0.097 \\
\hline & Biogas & -0.024 & 0.036 & 0.106 & $-0.207^{* * *}$ & 1 & 0.041 \\
\hline & Agricultural Residue & $-0.190^{* * *}$ & $0.111^{*}$ & $-0.208^{* * *}$ & -0.097 & 0.041 & 1 \\
\hline
\end{tabular}

***, $* *$ and $*$ indicate significance at the $1 \%$ and $5 \%$ and $10 \%$ levels, respectively.

\section{ACKNOWLEDGEMENT}

The authors acknowledge the support from ASALI project which was funded through the legacy of Late Ms Grietje Wille.

\section{REFERENCES}

[1] Lall, S.V., Overview: Africaâ€ $€^{\mathrm{TM}}$ s Cities: Opening Doors to the World. 2017.

[2] Van Noorloos, F. and M. Kloosterboer, Africa's new cities: The contested future of urbanisation. Urban Studies, 2018. 55(6): p. 12231241.

[3] Madlener, R. and Y. Sunak, Impacts of urbanization on urban structures and energy demand: What can we learn for urban energy planning and urbanization management? Sustainable Cities and Society, 2011. 1(1): p. $45-53$.

[4] Zhao, P. and M. Zhang, The impact of urbanisation on energy consumption: A 30-year review in China. Urban climate, 2018. 24: p. 940-953.

[5] Hove, M., E.T. Ngwerume, and C. Muchemwa, The urban crisis in SubSaharan Africa: A threat to human security and sustainable development. 2013.
[6] Goebel, A., Sustainable urban development? Low-cost housing challenges in South Africa. Habitat International, 2007. 31(3-4): p. 291-302.

[7] Rahut, D.B., A. Ali, and B. Behera, Domestic use of dirty energy and its effects on human health: empirical evidence from Bhutan. International Journal of Sustainable Energy, 2017. 36(10): p. 983-993.

[8] Freire, M.E., Urbanization and green growth in Africa. 2017.

[9]. Arnold, M. and R. Persson, Reassessing the fuelwood situation in developing countries. The International Forestry Review, 2003. 5(4): p. 379-383.

[10]. Mwampamba, T.H., Has the woodfuel crisis returned? Urban charcoal [consumption in Tanzania and its implications to present and future forest availability. Energy Policy, 2007. 35(8): p. 4221-4234.

[11] Hanif, I., Impact of economic growth, nonrenewable and renewable energy consumption, and urbanization on carbon emissions in SubSaharan Africa. Environmental Science and Pollution Research, 2018. 25(15): p. 15057-15067.

[12] Wang, J. and K. Dong, What drives environmental degradation? Evidence from 14 Sub-Saharan African countries. Science of the Total Environment, 2019. 656: p. 165-173.

[13] Kimutai, S., A. Kiprop, and D. Snelder, Household Energy Utilization and Changing Behaviours: Evidence from Western Kenya. 2019.

[14] Li, M., L. Li, and W. Strielkowski, The impact of urbanization and industrialization on energy security: A case study of China. Energies, 2019. 12(11): p. 2194. 
[15] Puttal, V. and N. Ravadi, Role of urban planning as tool to mitigate the environmental repercussions due to peri-urbanisation. Journal of Civil Engineering and Environmental Technology, 2014. 1(3): p. 96-102.

[16] Luo, C., et al., Modelling future patterns of urbanization, residential energy use and greenhouse gas emissions in Dar es Salaam with the Shared Socio-Economic Pathways. Journal of Cleaner Production, 2020. 254: p. 119998.

[17] Mandere, M., B. Ness, and S. Anderberg, Peri-urban development, livelihood change and household income: A case study of peri-urban Nyahururu, Kenya. Journal of Agricultural Extension and Rural Development, 2010. 2(5): p. 73-83.

[18] Karekezi, S., J. Kimani, and O. Onguru, Energy access among the urban poor in Kenya. Energy for Sustainable Development, 2008. 12(4): p. 38-48.

[19] Fobi, S., et al., A longitudinal study of electricity consumption growth in Kenya. Energy Policy, 2018. 123: p. 569-578.

[20] Karekezi, S. and W. Kithyoma, Renewable energy strategies for rural Africa: is a PV-led renewable energy strategy the right approach for providing modern energy to the rural poor of sub-Saharan Africa? Energy Policy, 2002. 30(11-12): p. 1071-1086.

[21] Dadashpoor, H. and S. Ahani, Explaining objective forces, driving forces, and causal mechanisms affecting the formation and expansion of the peri-urban areas: A critical realism approach. Land Use Policy, 2021. 102: p. 105232.

[22] Desa, U., World urbanization prospects, the 2011 revision. Population Division, Department of Economic and Social Affairs, United Nations Secretariat, 2014

23. Ondiba, H.A. and K. Matsui, Drivers of environmental conservation activities among rural women around the Kakamega forest, Kenya. Environment, Development and Sustainability, 2020: p. 1-13.

[24] Stoppok, M., et al., Of culture, consumption and cost: a comparative analysis of household energy consumption in Kenya, Germany and Spain. Energy Research \& Social Science, 2018. 40: p. 127-139.

[25] Ogut, J.O., Aquifer geometry and structural controls on groundwater potential in mount Elgon aquifer, Trans-Nzoia county, Kenya. 2015, University of Nairobi.

[26] Edwards, J.H. and C. Langpap, Startup costs and the decision to switch from firewood to gas fuel. Land Economics, 2005. 81(4): p. 570-586.

[27] Ouedraogo, B., Household energy preferences for cooking in urban Ouagadougou, Burkina Faso. Energy policy, 2006. 34(18): p. $3787-$ 3795.

[28] Zhang, D., J. Li, and P. Han, A multidimensional measure of energy poverty in China and its impacts on health: An empirical study based on the China family panel studies. Energy Policy, 2019. 131: p. 72-81.

[29] Van der Kroon, B., R. Brouwer, and P.J. Van Beukering, The energy ladder: Theoretical myth or empirical truth? Results from a metaanalysis. Renewable and Sustainable Energy Reviews, 2013. 20: p. 504-513.

[30] Van der Kroon, B., R. Brouwer, and P.J. Van Beukering, The impact of the household decision environment on fuel choice behavior. Energy Economics, 2014. 44: p. 236-247.

[31] Bisu, D.Y., A. Kuhe, and H.A. Iortyer, Urban household cooking energy choice: an example of Bauchi metropolis, Nigeria. Energy, Sustainability and Society, 2016. 6(1): p. 15.

[32] Duguma, L.A., et al., Deforestation and forest degradation as an environmental behavior: unpacking realities shaping community actions. Land, 2019. 8(2): p. 26.

[33] Choumert-Nkolo, J., P. Combes Motel, and L. Le Roux, Stacking up the ladder: A panel data analysis of Tanzanian household energy choices. World Development, 2019. 115: p. 222-235.

[34] Katikiro, R.E., Prospects for the uptake of renewable energy technologies in rural Tanzania. Energy Procedia, 2016. 93: p. 229-233.

[35] Sana, A., et al., Household energy choice for domestic cooking: distribution and factors influencing cooking fuel preference in Ouagadougou. Environmental Science and Pollution Research, 2020: p. 1-9.

[36] Maharaj, Y., Solar energy in peri-urban areas of Inanda, South Africa: examining attitudes and challenges. 2013.

[37] Munro, P., On, off, below and beyond the urban electrical grid the energy bricoleurs of Gulu Town. Urban Geography, 2020. 41(3): p. 428-447.

[38]. Shahsavari, A. and M. Akbari, Potential of solar energy in developing countries for reducing energy-related emissions. Renewable and Sustainable Energy Reviews, 2018. 90: p. 275-291.

[39] Behera, B. and A. Ali, Factors determining household use of clean and renewable energy sources for lighting in Sub-Saharan Africa. Renewable and Sustainable Energy Reviews, 2017. 72: p. 661-672.

[40] Lee, K., E. Miguel, and C. Wolfram, Appliance ownership and aspirations among electric grid and home solar households in rural Kenya. American Economic Review, 2016. 106(5): p. 89-94.

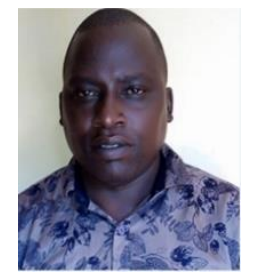

Mr. Stephen K. Kimutai was born in Uasin Gishu, Kenya on the $27^{\text {th }}$ May, 1979. He holds a Master of philosophy in Production Engineering (Manufacturing Technology Option) and is expected to graduate with $\mathrm{PhD}$ in Energy Studies in December 2021. He holds a Bachelor's degree in Mechanical and Production Engineering from Moi University.

$\mathrm{He}$ is a senior lecturer, Department of Mechanical, Production \& Energy Engineering, School of Engineering, Moi University. In addition, Kimutai is the School of Engineering Timetable Coordinator.

Mr. Kimutai is a registered Graduate Engineer with Engineers Board of Kenya. He was awarded scholarship to pursue Msc degree as a result of his First-class Honours in Bachelor's degree by Higher education loans board. $\mathrm{He}$ is also a research member of ASALI project.

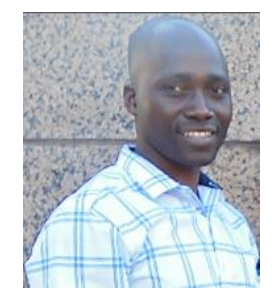

Dr. Stephen M. Talai was born on $16^{\text {th }}$ August, 1982 in Marakwet District, Kenya. He earned his PhD (Mechanical Engineering) from Tshwane University of Technology, Pretoria, South Africa in 2017, Msc (Renewable Energy Option) in 2012 and Bachelor of Technology (Mechanical and Production Engineering) in 2007 both from Moi University, Eldoret, Kenya.

$\mathrm{He}$ is a Lecturer of Solar Energy and Mechanical Dynamics, Department of Mechanical, Production \& Engineering, Moi University.

Dr. Talai is a registered Graduate Engineer with Engineers Board of Kenya and trained Asset Manager by Pragma academy of South Africa. He was awarded scholarship to pursue MSc degree as a result of his First-class Honours in Bachelor's degree. Also, he worn ESKOM scholarship of South Africa in 2014 to pursue his $\mathrm{PhD}$ from a joint project of University of Pretoria and Tshwane University of Technology. Currently, he is a research member of Transforming Energy Access - Learning and Partnership in Sub-Saharan Africa. 